v.23, n.1, Especial do IV Simpósio de Nutrição de Animais de Companhia, p.01-02, 2018

\title{
SUJIDADES LEVES EM ALIMENTOS EXTRUSADOS PARA CÃES COMERCIALIZADOS A GRANEL E EM EMBALAGEM FECHADA NA REGIÃO DA GRANDE FLORIANÓPOLIS
}

(Light filth in extruded foods for dogs sold in bulk and closed packaging in the region of Greater Florianópolis)

Juliana R. da Silva', Marcella N. Pereira', Lívia C. Escatolin¹, Elisa H. Moecke², Vildes M. Scussel¹

\author{
'Laboratório de Micotoxinas e Contaminantes Alimentares, Universidade Federal de Santa Catarina, \\ Florianópolis, SC. \\ ²Laboratório de Engenharia Ambiental Sanitária, Universidade do Sul de Santa Catarina, Palhoça, SC. \\ E-mail: jusilva.zootecnista@gmail.com
}

Resumo: Foi avaliada a presença de sujidades leves em alimentos extrusados para cães comercializados a granel e em embalagem fechada, bem como as condições ambientais de comercialização. Foram analisadas 25 amostras a granel e 25 embalagens fechadas. Quanto a sujidades leves, 34\% tiveram alguma sujidade detectada, sendo $30 \%$ delas em alimentos comercializados a granel. A principal sujidade encontrada foi os fragmentos de insetos, $40 \%$ nas amostras a granel e $8 \%$ em embalagem fechada. Em relação à condição de comercialização, dos 16 comércios visitados, 4 tinham condições higiênicas sanitárias baixas com alimentos expostos ao ambiente, acesso a outros animais e local empoeirado. Condições ambientais inadequadas, como as observadas nos alimentos a granel, associadas à falta de boas práticas de comercialização, contribuem para o aumento da presença de vetores, como roedores e insetos.

Palavras-chave: cão; contaminantes; insetos

Abstract: The presence of light filth in extruded foods for dogs commercialized in bulk and closed packaging, as well as the environmental conditions of commercialization were evaluated. Were analyzed 25 samples in bulk and 25 closed packages. About light filths, $34 \%$ had some filth detected, $30 \%$ of them in foods commercialized in bulk. The main soil found was insect fragments, $40 \%$ in bulk samples and $8 \%$ in sealed packages. Of the 16 trades visited, 4 had low hygienic sanitary conditions with food exposed to the environment, access to other animals and dusty place. Inadequate environmental conditions, such as those observed in bulk foods, associated with poor marketing practices, contribute to the increased presence of vectors such as rodents and insects.

Keywords: dog; contaminants; insects

Introdução: Um fator importante que afeta seriamente a qualidade e segurança dos alimentos é a presença de insetos, ácaros e roedores. A presença desses contaminantes é considerada um indicativo de falta de controle higiênico-sanitário durante a colheita e armazenamento da matéria-prima, nas condições de processamento aplicadas, bem como a eficiência no acondicionamento do produto final e sua comercialização (Lorini, 2002; de Souza Koerich \& Scussel, 2013).

No que se refere às condições de venda de alimentos extrusados para animais, em alguns países existe um hábito inadequado de vendê-los a granel, em pequenas porções retiradas de sacos abertos que permanecem nas lojas durante dias até o fim do seu conteúdo. A comercialização de alimentos vendidos dessa maneira permite a contaminação de organismos vivos, que podem estar presentes no ambiente (Machado et al., 2008). 
Considerando a falta informação sobre a presença de sujidades leves em alimentos para animais de estimação, o objetivo deste estudo foi avaliar os alimentos extrusados para cães, vendidos a granel e em embalagem fechada, e sua relação com as condições ambientais de comercialização.

Material e Métodos: Foram analisadas 25 amostras vendidas a granel e 25 em embalagens fechadas de alimentos comerciais extrusados para cães, coletados randomicamente em agropecuárias, pet shops e mercados em relação a sujidades leves pelo método oficial da AOAC (2005). Observaram-se também as condições ambientais de comercialização: local de armazenagem das rações a granel e em embalagem fechada; higiene e ventilação da loja, assim como a integridade das embalagens.

Resultados e Discussão: Das 50 amostras analisadas, 17 apresentaram algum tipo de sujidade leve. As rações vendidas a granel foram as que continham um maior número de sujidades leves detectadas (63\%) em relação à embalagem fechada (8\%). As principais sujidades encontradas foram insetos inteiros e fragmentos, assim como pelos de roedores (Figura 1). Esses resultados corroboram com os encontrados por outros autores (de Souza Koerich \& Scussel, 2013; Sousa, 2005), onde a sujidade leve detectada foi maior em alimentos comercializados a granel.

Dos 16 estabelecimentos visitados, $25 \%$ apresentaram condições higiênicas sanitárias inadequadas.
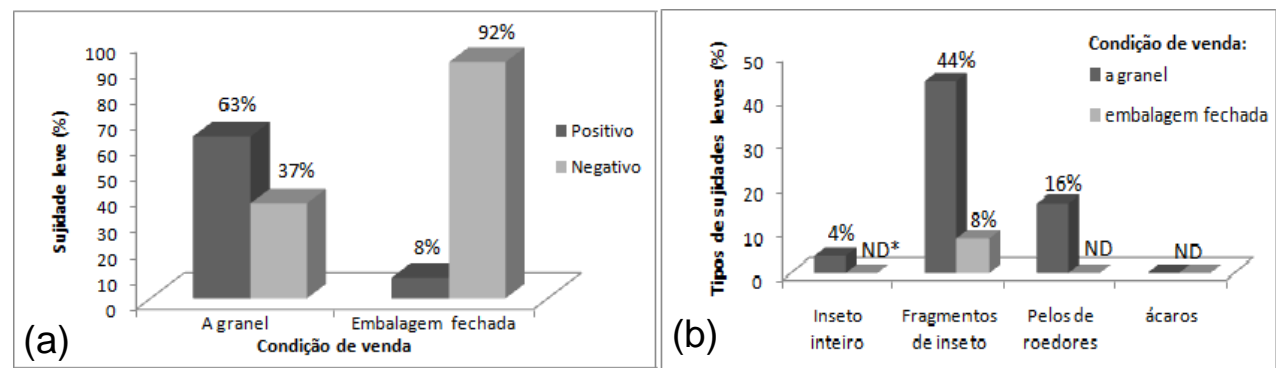

Figura 1. Sujidades leves em alimentos extrusados para cães, comercializados a granel e em embalagens fechadas (a) sujidade total e (b) tipos de sujidades encontradas.

Conclusão: Condições ambientais inadequadas, associadas à falta de boas práticas de comercialização, contribuem para o aumento da presença de vetores como roedores e insetos. Todas as embalagens estavam intactas.

Referências: LORINI, I. Descrição, biologia e danos das principais pragas de grãos armazenados. In: Lorini, Miike, Scussel, Armazenagem de Grãos. Ed. Biogeneziz, Campinas SP, 2002. p.381-397.

DE SOUZA KOERICH, K.; SCUSSEL, V.M. Dogs and birds dry food fumonisin FB 1 and $\mathrm{FB}_{2}$ contamination and their relation to ingredients and packaging characteristics. Research Journal of Biological Sciences, 8: p.22-29.2013.

AOAC. Association of Official Analytical Chemists. Official methods of analysis of AOAC International. Gaithersburg (MD).2005.

SOUSA, J.M. Monitoramento de insetos em grãos de milho e feijão e em rações comercializadas em Recife,. Revista Brasileira de Armazenamento, 30(2): p.186191. 2005. 